\title{
Verbal content analysis for the study of Verisimilitude (V1) in the System for Analysis of Validity in Evaluation (SAVE)
}

DOI: $10.46932 / \mathrm{sfjdv2n2-204}$

Received in: March 1st, 2021

Accepted in: May 30th, 2021

\section{Marta Grau Olivares}

Behavior \& Law Research Foundation, Madrid, Spain.

E-mail: mgrau@behaviorandlaw.com

\section{VERISIMILITUDE OR INTERNAL COHERENCE.}

In the SAVE Metaprotocol (López, et al, 2018), Verisimilitude (V1) refers to that which has the appearance of truth, possibility of being believed, and with "absence of subjective incredibility".

Corresponding to this section is everything related to the analysis of the content of the verbal message and which gives internal coherence to the subject's statement. This phase is obtained directly through the interview with the subject, which we record in order to be able to carry out the content analysis later. It can be using a criterial, structural, or linguistic analysis, or simply employing a study of the communicative pattern.

Some examples of content analysis are Statement Validity Analysis (SVA) with its Criteria-Based Content Analysis or CBCA and its validity list. The CBCA is composed of 19 criteria used to assess the content of the statements and which to date has been admitted as court evidence in cases of possible child sexual offense. It is administered together with a validity checklist and its value as evidence depends on the scope of application (Köhnken, Manzanero \& Scott 2015).

The instrument called Reality Monitoring (RM), like the previous one is a tool used to assess the credibility of the testimony and that focuses on the semantic aspects that differentiate a true statement from a false or not very credible one (Raye \& Johnson, 1980). Although in this aspect, we should not make the mistake of confusing credibility with veracity, since when assessing a testimony the truth as such does not exist, and depends on the functioning of our memory, which is not like a tape recorder and is not static, but is constantly exposed to changes and distortions. According to this model, the origin of our memories comes from two basic sources: External Memories, generated from the perception of real situations; and Internal Memories, the product of our imagination. The unconscious reasoning process that our mind follows to decide which information comes from an external source and which forms an internal one is called Reality Monitoring. Four qualitative attributes allow us to differentiate between these two types of memories: 
1. Contextual attributes (temporospatial information).

2. Sensory Attributes (visual, auditory, tactile details...).

3. Semantic details.

4. Cognitive Operations (reflections and thoughts of the subject).

Depending on how these four elements are organized in our memories, their origin can be determined, so that external (perceived) memories present a greater amount of contextual, sensory (smells, colors, sounds...) and semantic information than internal memories, which, on the contrary, will be richer in cognitive operations (Masip, Garrido \& Sporer, 2005).

In the structural analysis of the verbal message (Adams, 1996), the proposal of balance or protagonism of the main story stands out after separating the statement into Beginning, Middle, and End, in the stories considered truthful. The linguistic analysis would incorporate specific techniques such as those of Pennebaker (Pennebaker, 2011) who obtain surprising conclusions by analyzing the use of pronouns, or others.

In SAVE this section can be as extensive as necessary, combining several of the techniques discussed, for example, but also using a method as simple as the study of the communicative pattern or style: False Style (uncertainty, vagueness, evasiveness, etc.) and Truthful Style (simplicity, order, balance, amount of detail).

Some authors propose new strategic lines (Masip and Herrero, 2015b) that are included in SAVE, such as the development of active interview strategies, to be applied both in V1 and in the second stage of Veracity (V2). An example of this would be the use of the technique called the Verifiability Approach (Vrij \& Nahari, 2019). in V1 (subjects who lie tend not to give details in their statements, but if asked will give many details but which are not subsequently verifiable), which may allow verifiable details obtained to be checked in V3.

\section{CONCLUSIONS.}

In this first phase of SAVE or V1, it is essential to adequately collect as broad and 'clean' an account as possible, avoiding suggesting or contaminating the statement, which can then be thoroughly analyzed both verbally and in its congruence with the non-verbal to establish, respectively, the degree of Verisimilitude (V1) and Veracity (V2).

The attitude of the researcher/interviewer would be that of 'humble inquiry' (Schein, 2013) since it is ideal due to the asymmetry of information in favor of the interviewee or specialists.

The interviewee should be encouraged to express him/herself freely by asking open-ended questions such as: 'What happened to you' or even 'Please tell me about it'. 
We should avoid interrupting him/her since the more he/she says, the more useful information we will be able to obtain to decide if we are dealing with a sincere response style or not.

In this phase we can also analyze the content of the documentation provided (reports, parts, statements, etc.), thus supporting the Verification phase (V3), with which it has several synergies as in the Verifiability Approach technique.

Keywords: SAVE metaprotocol, verisimilitude, statement content analysis, communicative style, credibility. 


\section{REFERENCES}

Adams, SH (1996). Statement analysis: What do suspect's words really reveal? FBI Law Enforcement Bulletin. 12-20.

Blandón-Gitlin, I., López, R.M, Masip, J. \& Fenn, E. (2017). Cognition,emotion and lying:implications for detecting deception.Yearbook of Legal Psychology, 27, 95-100.

Domínguez-Muñoz, A., López, R. M., Gordillo, F., Pérez-Nieto, M. A., Gómez, A. \& De la Fuente, J. L. (2014). Scientific and bioethical bases of validity analysis in evaluative medicine. Medicina y Seguridad en el Trabajo, 236, 527-535.

Domínguez-Muñoz, A., De la Fuente, J. L., Gómez, A. M., García, P., López M. J., \& López, R. (2017). Behavioral Analysis in Evaluative Medicine: an interdisciplinary proposal. Occupational Medicine and Safety. 63(248), 260-275.

Köhnken, G., Manzanero, A. L., \& Scott, M. T. (2015). Statement Validity Analysis (SVA): myths and limitations. Yearbook of Legal Psychology, 25, 13-19.

López, R. M., Domínguez-Muñoz, A., Grau, M., Juárez, A., Jiménez, J., \& Garrido, M. J. (2018). SAVE metaprotocol for behavior analysis. An integrative proposal. In E. Arias, J. Sanmarco, \& X. Camplá (Eds.), XI International Congress of Legal and Forensic Psychology. (pp. 528-541). Granada: Spanish Society of Legal and Forensic Psychology.

Manzanero, A. L., \& González, J. L. (2015). Holistic model for the evaluation of testimonial evidence (HELPT). Papeles del Psicólogo, 36(2),125-138.

Masip, J., Garrido, E. and Sporer, S.L.. (2005) Detection of deception with the Reality Monitoring approach: A Review of the Empirical Evidence. Psychology, Crime and Law, 11(1), 99-122.

Masip, J. \& Herrero, C. (2015a). New approaches in lie detection I. Background and theoretical framework. Papeles del Psicólogo, 36, 83-95.

Masip, J. \& Herrero, C. (2015b). New approaches in lie detection I. Background and theoretical framework. Papeles del Psicólogo, 36, 96-108.

Pennebaker, JW (2011). The secret Life of Pronouns: What aour words say about us. 1st Edition. New York: Bloomsbury, USA.

Raye, C.L. and Johnson, M.K. (1980). Reality Monitoring vs. Discriminating Between External Sources of Memories. Bullerin of the Psyconomic Society, 15(6), 405-408.

Schein, EH (2013). Humble Inquiry: The gentle art of asking instead of telling. 1st Edition. San Francisco: Berrett-Koeheler Publishers, Inc.

Vilalta, R. J., Winberg, M. (2016) Functional behavior analysis in the forensic psychological assessment of testimony credibility. Behavior \& Law Journal 2 (1), 1-10.

Vrij, A., \& Nahari, G. (2019). The verifiability approach. Evidence-based investigative interviewing, 116133. 